\title{
Study of the Processing of a Recycled WC-Co Powder: Can It Compete with Conventional WC-Co Powders?
}

\author{
Alexandre Mégret ${ }^{1}\left[\right.$ Céronique Vitry $^{1} \cdot$ Fabienne Delaunois $^{1}$
}

Received: 18 September 2020 / Accepted: 10 February 2021 / Published online: 17 March 2021

(c) The Author(s) 2021

\begin{abstract}
Cemented carbide tools suffer from many issues due to the use of tungsten and cobalt as raw materials. Indeed, those are listed by the European Commission as "critical raw materials" since 2011 and by the US Department of Interior as "critical minerals" in 2018. To remain competitive with the conventional high-speed steels, less performant but cheaper, WC-Co tools can be recycled. In the present paper, a WC-7.5Co powder, recycled by the "Coldstream" process, has been sintered with vacuum sintering. As preliminary experiments have shown that the sinterability of the powder is low, the sintering temperature was set at $1500^{\circ} \mathrm{C}$ to achieve full density. In parallel, the influence of ball milling conditions (rotation speed and milling medium) on the reactivity of the recycled powder has been studied in terms of grain size distribution, hardness, and fracture toughness. The optimized milling conditions were found to be $6 \mathrm{~h}$ wet milling, leading to a hardness of about $1870 \mathrm{HV}_{30}$ and a toughness of about $10.5 \mathrm{MPa} \sqrt{ } \mathrm{m}$ after densification. The recycled powder can thus totally compete with conventional powders, opening avenues for the recycling of cemented carbide tools.
\end{abstract}

\section{Graphical Abstract}

ISSUE

Co and $\mathrm{W}=$ Critical raw materials
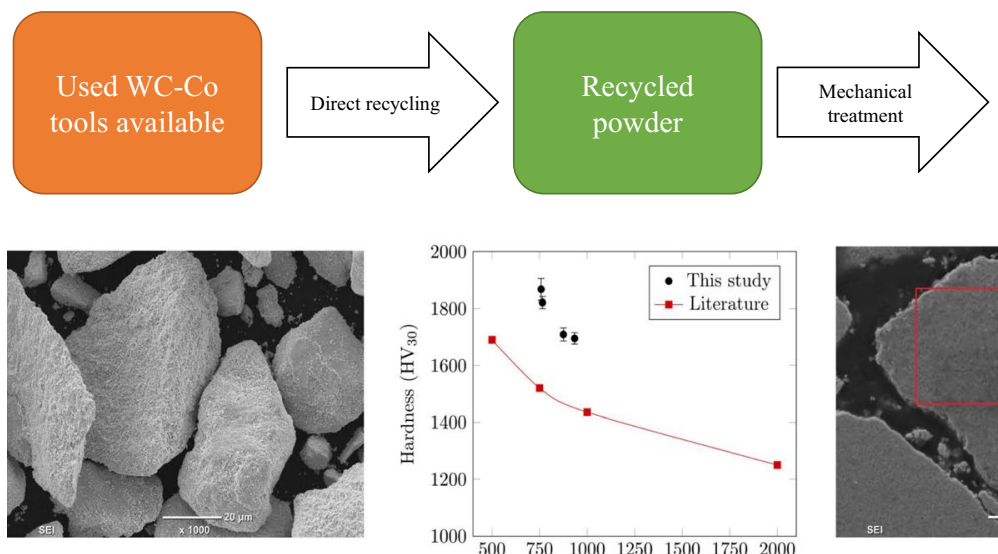

Ready-to-sinter powder
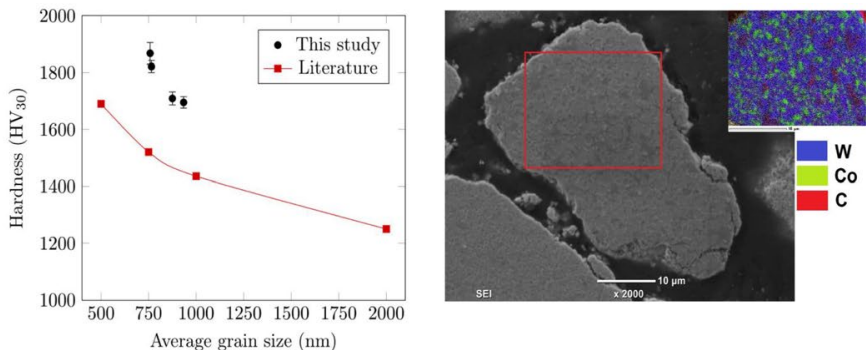

Keywords Recycled powder $\cdot$ Sintering $\cdot$ Cemented carbides $\cdot$ Milling

The contributing editor for this article was João António Labrincha Batista.

Extended author information available on the last page of the article 


\section{Introduction}

In the last 50 years, new issues have appeared regarding the supply and demand of natural resources and raw materials [1-5]. In the field of cemented carbides, the price of cobalt has recently increased a lot due to the demand for cobalt for the batteries of electric vehicles [6]. Moreover, only $2 \%$ of cobalt comes from primary extraction; the other $98 \%$ is obtained from by-products of nickel or copper mining [7, 8]. A little less than 50 percent of the world's cobalt production is mined in only one country, the Democratic Republic of the Congo (DRC), a politically unstable country. For example, in 1978, a cobalt supply crisis due to military activity in the region of DRC where the copper mines are situated has caused a supply shortage and an increase of cobalt price on the world market [3].

However, cobalt is the most compatible binder for cemented carbides [9-11]: mixed with tungsten carbide WC, it creates a eutectic compound which lowers the melting temperature and thus the processing temperature (more than $2800{ }^{\circ} \mathrm{C}$ for pure WC versus $1300-1500{ }^{\circ} \mathrm{C}$ with adequate Co additions). Also, wettability of the carbide phase by cobalt is excellent and WC is easily soluble in cobalt. The two last points are crucial for liquid phase sintering in vacuum (the usual time-temperature conditions are $1 \mathrm{~h}$ at $1400{ }^{\circ} \mathrm{C}$ [12] with a relatively low heating rate-around $4{ }^{\circ} \mathrm{C} / \mathrm{min}$ - to ensure thermal equilibrium). The use of cobalt in cemented carbides provides excellent hardness to toughness ratio and wear properties [13, 14]. Alternatives to cobalt exist: nickel, iron, and copper [15-17] are nowadays used as binders even if they are less efficient than cobalt. Nickel is usually used when corrosion resistance is needed [18]. Iron and copper are generally not used alone but are coupled with nickel or cobalt. More recently, high entropy alloys $[19,20]$ have been utilized as binders for cemented carbides.

Recycling methods for the recovery of tungsten carbide tools are divided into three main categories [21-23]: the direct methods in which the scraps are transformed into powders with the same composition (usually reserved for high purity grades); the indirect methods in which the scraps are converted into intermediate products, mainly into APT - ammonium paratungstate (e.g., electrochemical processes [23-25], chlorination [26, 27]); and the semiindirect methods which involve a selective dissolution of one component, generally the binder (e.g., acid leaching or selective electro-dissolution [28-31]). Direct methods present many advantages (high recovery rates, good quality of the powders, good grain materials) but some drawbacks (difficult separation of the binder and need for costly materials and equipment). The zinc method [32-35] and the Coldstream process $[23,36]$ are the two main direct methods. In the zinc method, molten zinc $\left(900-1050{ }^{\circ} \mathrm{C}\right)$ infiltrates the WC-Co scraps, reacts with the binder, and forms intermetallic compounds (especially a zinc-cobalt alloy). A vacuum distillation (pressure is about $10 \mathrm{~Pa}$ ) is then used to eliminate the $\mathrm{Zn}-\mathrm{Co}$ alloy. In the Coldstream process, the WC-Co scraps are cooled down, accelerated, and then projected towards a target plate. Due to the high energy involved in the process, the scraps are crushed into small particles.

Ball milling is widely used in tungsten carbide preparation to ensure a good homogenization of the different powders as well as to induce "mechanical alloying" [37, 38]. The influence of ball milling parameters (medium, balls diameter, time) has been studied in different papers [39-44].

In 2010 , around $25 \%$ of the tungsten came from end-oflife scrap recycling [45]. However, despite lower energy consumption for its processing, the total cost of recycled tungsten carbide powders is not cheaper than extracting tungsten from concentrates, usually due to the high price of tungsten scraps compared to tungsten ores [45]. It will be difficult to substitute the primary production of tungsten completely. However, the increase in recycling could enhance the secondary supply of tungsten (the main advantages are the elimination of rock mining operations, the lower energy required, and the decrease of carbon emissions) and could lead to positive environmental effects. Recycling used cutting tools is an interesting option to keep the benefits of cobalt as a binder and to limit the issues linked to its production. In this work, a recycled WC-Co powder has been sintered by conventional processes and subsequently characterized. Ball milling experiments have also been carried out to study the sinterability of the powder.

\section{Experimental Procedure}

The powder has been provided by the Höganäs S.A. Belgium company (powder PA2-45). Used cutting tools have been crushed and transformed into ready-to-sinter powder by the "Coldstream process." The Coldstream process is based on the mechanical comminution of the scraps [36]. The powder contains $7.5 \mathrm{wt} . \%$ cobalt and some chromium from $\mathrm{Cr}_{3} \mathrm{C}_{2}$ that is added as a grain-growth inhibitor. The average particle size is $45 \mu \mathrm{m}$. Two different treatments (Fig. 1) have been applied to the recycled powder. On one hand (experiment A), the powder has been mixed with $1 \mathrm{wt} . \%$ zinc stearate for $1 \mathrm{~h}$ in a 3D shaker mixer (Turbula®, WAB-Group Muttenz, Switzerland) to ensure good forming properties of the powder during uniaxial cold pressing. On the other hand (experiments B-E), the recycled powder has been ball milled for $6 \mathrm{~h}$ (effective milling time).

The grinding was carried out in a Fritsch Pulverisette 7 premium line planetary ball mill (Markt Einersheim, 


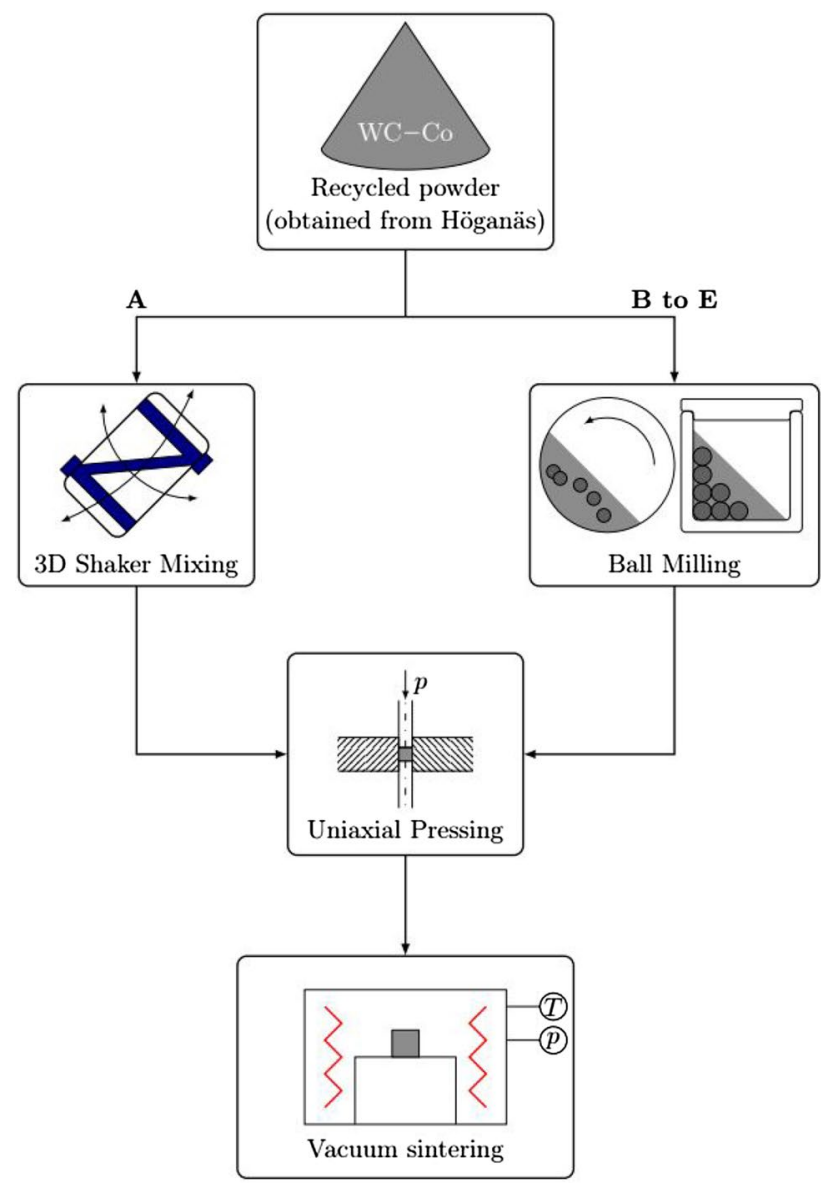

Fig. 1 Flowchart of the sample preparation process

Table 1 Ball milling conditions

\begin{tabular}{|c|c|c|}
\hline Experiment & Rotation speed (rpm) & Milling medium \\
\hline A & \multicolumn{2}{|c|}{ Turbula mixed powder } \\
\hline $\mathrm{B}$ & 300 & Dry (zinc stearate) \\
\hline $\mathrm{C}$ & 300 & Wet (ethanol) \\
\hline $\mathrm{D}$ & 600 & Dry (zinc stearate) \\
\hline $\mathrm{E}$ & 600 & Wet (ethanol) \\
\hline
\end{tabular}

Germany). Tungsten carbide bowls and balls were used to avoid contamination of the powder. The milling was undertaken with balls of $10 \mathrm{~mm}$ in diameter in three separate stages of $2 \mathrm{~h}$ each. The influence of the rotation speed (300 rpm and $600 \mathrm{rpm}$ ) and the milling medium (dry or wet) has been analyzed (Table 1). Two samples have been sintered for every set of powder processing conditions. A study by Stanciu et al. [46] has demonstrated that ethanol is an adequate wet milling medium to avoid oxidation of the cobalt phase during milling. Samples have been dried in an oven at $100{ }^{\circ} \mathrm{C}$ for $12 \mathrm{~h}$. Zinc stearate was chosen as a dry milling medium. Zhang et al. [39] have shown that the dry milling conditions allow the obtention of smaller grains in agglomerated particles while wet milling provides better dispersion of the particles [42].

The powders have been cold-pressed under $500 \mathrm{MPa}$ with a uniaxial press before sintering in a vacuum furnace. Sintering, achieved in a tubular ThermConcept furnace (Bremen, Germany), has been undertaken at $1500{ }^{\circ} \mathrm{C}$ under vacuum (pressure lower than $10^{-3} \mathrm{MPa}$ ) with a heating rate of $4{ }^{\circ} \mathrm{C} / \mathrm{min}$. The thermal cycle contains three dwelling steps: the first one at $350{ }^{\circ} \mathrm{C}$ for dewaxing, the second one at $950{ }^{\circ} \mathrm{C}$ for the diffusion of grain-growth inhibitors, and the last one at $1500{ }^{\circ} \mathrm{C}$ for sintering. The samples are maintained at the sintering temperature for $1 \mathrm{~h}$.

The density of the samples is measured by Archimedes' principle and densification $D(\%)$ is calculated by Eq. (1) in which $\rho_{\text {meas }}$ is the measured density $\left(\mathrm{g} / \mathrm{cm}^{3}\right)$ and $\rho_{\text {theo }}$ is the theoretical density $\left(\mathrm{g} / \mathrm{cm}^{3}\right)$.

$D=\frac{\rho_{\text {meas }}}{\rho_{\text {theo }}} \times 100$

The samples are mounted into a resin, polished, and etched by Murakami reagent (mixture containing $5 \mathrm{~g}$ of potassium ferricyanide, $5 \mathrm{~g}$ of sodium hydroxide, and $50 \mathrm{ml}$ of deionized water) to reveal their microstructure and to characterize the apparent porosity (according to the ASTM B276 standard). Type A porosity refers to pores with a size inferior to $10 \mu \mathrm{m}$. In type B, the pores' size is comprised between 10 and $25 \mu \mathrm{m}$ while type $\mathrm{C}$ refers to the pores induced by free carbon. The latter are obtained when carbon is in excess within the sample and result from uncombined carbon. Hardness measurements have been performed with a Vickers indenter under $30 \mathrm{~kg}$ load (EMCO-Test M4U-025 device, Hallein, Austria) for $20 \mathrm{~s}$. Ten measurements have been realized per sample. The fracture toughness of the samples is deduced from macro-hardness $[47,48]$ as shown by Palmqvist's Eq. (2).

$K_{1 c}=A \sqrt{\frac{H V_{30}}{\sum l}}$

where $K_{1 c}$ is the stress intensity factor $(\mathrm{MPa} \sqrt{ } \mathrm{m}), A$ is a constant, $H V_{30}$ is the Vickers macro-hardness under $30 \mathrm{~kg}$ load $\left(\mathrm{HV}_{30}\right)$, and $\sum l$ is the sum of the length of the cracks $(\mathrm{mm})$ that appeared at the corners of the print. The lengths of the cracks have been measured with a Leica optical microscope (Wetzlar, Germany).

Scanning electron microscopy (JEOL-6000Plus Versatile Benchtop SEM-accelerating voltage 10 and $15 \mathrm{kV}$-Tokyo, Japan) equipped with energy-dispersive $\mathrm{X}$-rays spectrometry (EDX) is carried out to characterize the powder and the sintered materials. The samples have 
been metalized with platinum for $20 \mathrm{~s}$ before analysis. The grain size distribution has been calculated from the SEM images using the linear intercept method. The carbon and oxygen contents have been characterized using LECO devices (Geleen, The Netherlands).

\section{Results and Discussion}

\section{Recycled Powder Characterizations}

The morphology of the recycled powder, characterized by SEM, is shown in Fig. 2. The largest dimension of the particle $(45 \mu \mathrm{m})$ is in good agreement with the powder's average particle size. The particle contains many submicron grains. The EDX analysis confirms the presence of tungsten and cobalt in the particle as shown on the elemental mapping of Fig. 2b. The grain size distribution (Fig. 2c) is wide and the powder contains grains up to $3.5 \mu \mathrm{m}$ size, a consequence of the first life of the tool (first sintering). The average grain size is $1.1 \pm 0.6 \mu \mathrm{m}$. The grains have a faceted shape due to the presence of a liquid phase during the sintering $[49,50]$.
Table 2 Carbon and oxygen contents (in the powders)

\begin{tabular}{lll}
\hline Experiment & Carbon (wt.\%) & Oxygen (wt.\%) \\
\hline A & $6.425 \pm 0.035$ & $0.165 \pm 0.008$ \\
B & $6.365 \pm 0.035$ & $0.803 \pm 0.036$ \\
C & $5.855 \pm 0.015$ & $0.768 \pm 0.004$ \\
D & $6.355 \pm 0.005$ & $1.095 \pm 0.025$ \\
E & $5.965 \pm 0.005$ & $1.060 \pm 0.010$ \\
\hline
\end{tabular}

\section{Physical Properties and Microstructures}

Table 2 presents the carbon and oxygen contents in the different powders. The stoichiometric carbon content has been calculated at $5.67 \mathrm{wt} . \% \mathrm{C}$ for a cemented carbide containing 7.5 wt.\% cobalt. The powders contain more carbon than the stoichiometric value, probably due to the use of zinc stearate as lubricant or ethanol as milling medium. On one hand, zinc stearate is an organic compound with the formula $\mathrm{C}_{36} \mathrm{H}_{70} \mathrm{O}_{4} \mathrm{Zn}$ bringing carbon and oxygen atoms into the powder. On the other hand, despite the powder's drying at $100{ }^{\circ} \mathrm{C}$, carbon atoms from ethanol could remain on the powder and thus increase the carbon content. The powders milled in ethanol (experiments $\mathrm{C}$ and $\mathrm{E}$ ) present a carbon content lower than that of the dry-milled powders.
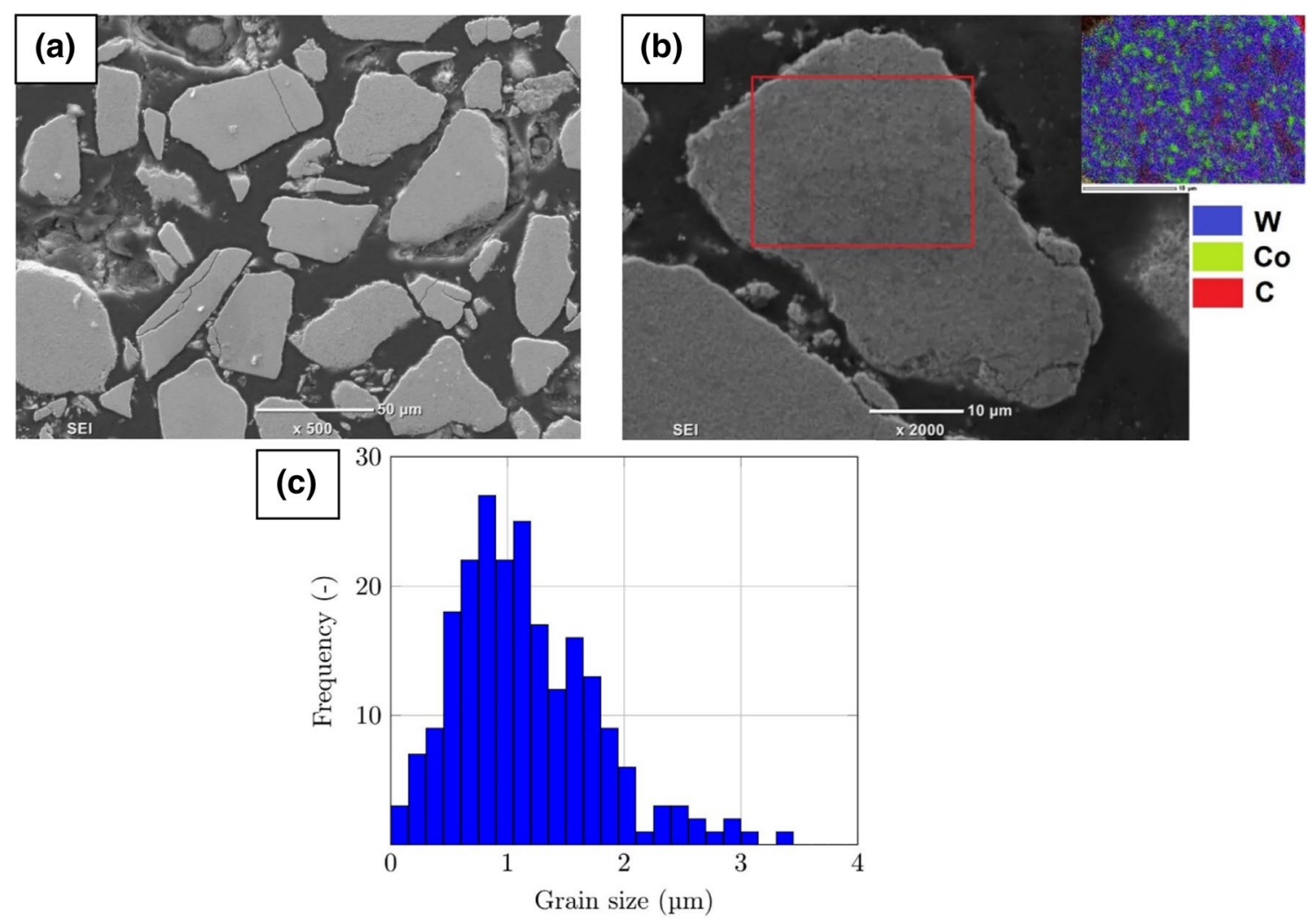

Fig. 2 SEM microstructure of recycled powder particles: $\mathbf{a} \times 500, \mathbf{b} \times 2000$ and EDX analysis, $\mathbf{c}$ grain size distribution 
The wet-milled powders are therefore more prone to the formation of the brittle eta-phase. The rotation speed does not influence the carbon content. The oxygen content has been increased with the ball milling step and is higher in the case of higher rotation speed. This is probably due to the higher temperatures involved during high-energy millings and to the presence of finer particles. The use of ethanol as the milling medium has been reported in the literature to increase the oxygen content in cemented carbide powders [51]: the oxygen atoms can be adsorbed on the powder particles' surface or dissolved in the interspace of the powder particles. These considerations suggest that the best milling parameters for the recycled powder are milling at lower rotation speeds to reduce the oxygen content and milling in dry conditions to have a sufficient carbon content that will avoid the formation of the eta-phase during sintering. Eta-phase, as well as free carbon, is detrimental to mechanical properties (hardness and toughness) in cemented carbides [52].

In high-energy ball milling, three mechanisms compete: fracture of the particles, cold welding of the particles, and plastic deformations. The preponderance of those mechanisms essentially depends on the milling speed and time. At low milling time, cold welding and plastic deformation are predominant. By increasing the milling time, the particles become work-hardened, are less prone to deformation, and thus fracture into smaller particles [53, 54]. For the same rotation speed, the SEM pictures (Fig. 3) show that dry milling contains more agglomerates. The powder from experiment B (dry milling at a rotation speed of $300 \mathrm{rpm}$ ) admits a bimodal distribution with an average of $12.2 \pm 4.0 \mu \mathrm{m}$ for the biggest particles. An increase of the rotation speed to $600 \mathrm{rpm}$ reduces the average size of the biggest particles at $9.1 \pm 2.5 \mu \mathrm{m}$. No agglomerates over $25 \mu \mathrm{m}$ were found within the dry-milled powders. Higher rotation speed increases the impact energy, accelerates the milling efficiency, and thus reduces the size of particles. In wet ball milling, the influence of rotation speed is not clearly observed, the powders contained a few large dispersed agglomerates from 30 to $100 \mu \mathrm{m}$. However, the powders are finer than the dry milling ones with the biggest particles (agglomerates excepted) of $5.9 \pm 1.5 \mu \mathrm{m}$ for experiment $\mathrm{C}(300 \mathrm{rpm})$ and $7.3 \pm 2.4 \mu \mathrm{m}$ for experiment $\mathrm{E}(600 \mathrm{rpm})$. These results are in good agreement with the study of Zhang et al. [39].

The densities of the different samples after sintering are presented in Fig. 4. Experiment A presents the lowest density (densification is about $83 \%$ ). Consequently, without any ball milling, the sinterability of the recycled powder is low even at $1500{ }^{\circ} \mathrm{C}$. However, every ball milling experiment has led to an average density higher than $95 \%$. The density measurements suggest that experiment $\mathrm{C}$ gives the
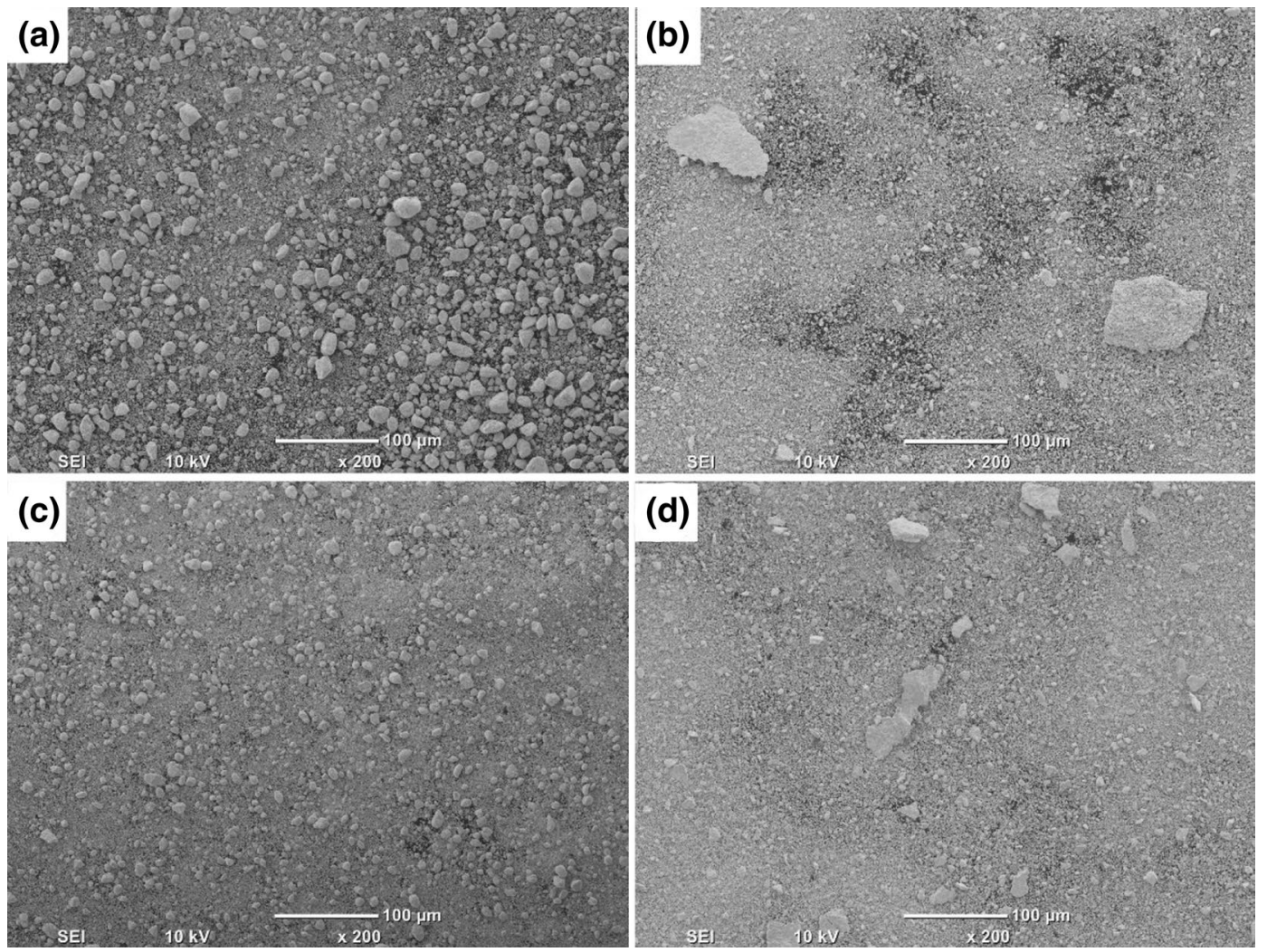

Fig. 3 SEM pictures of the powders: a 300 rpm-dry-exp B; b 300 rpm-wet-exp C; c 600 rpm-dry-exp D; d 600 rpm-wet-exp E 


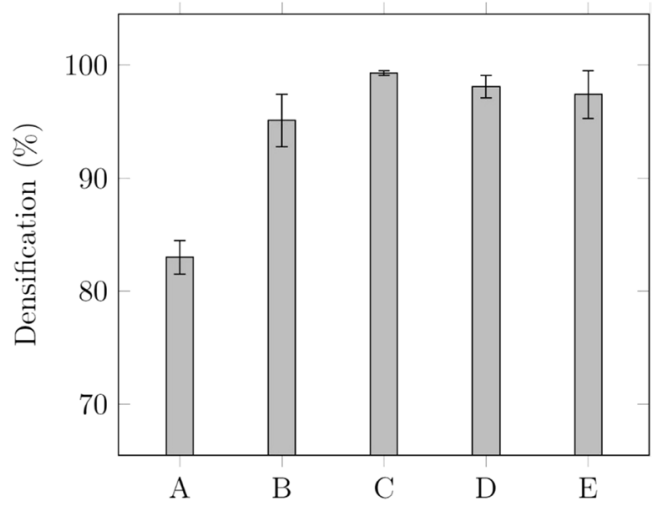

Fig. 4 Densification of the samples after sintering at $1500{ }^{\circ} \mathrm{C}$ for $1 \mathrm{~h}$ : $A$ turbula mixed power, $B$ dry milling at $300 \mathrm{rpm}, C$ wet milling at $300 \mathrm{rpm}, D$ dry milling at $600 \mathrm{rpm}, E$ wet milling at $600 \mathrm{rpm}$

Table 3 Porosity characterization according to the ASTM standard B276

\begin{tabular}{llll}
\hline Experiment & $\begin{array}{l}\text { Type A } \\
(\text { vol.\%) } \\
(\leq 10 \mu \mathrm{m})\end{array}$ & $\begin{array}{l}\text { Type B (vol.\%) } \\
(>10 \mu \mathrm{m} \\
\text { and } \leq 25 \mu \mathrm{m})\end{array}$ & $\begin{array}{l}\text { Type C } \\
(\text { vol.\%) (free } \\
\text { carbon) }\end{array}$ \\
\hline B & 0.60 & 0.02 & No type C \\
C & 0.06 & No type B & No type C \\
D & 0.20 & 0.02 & No type C \\
E & 0.06 & 0.02 & No type C \\
\hline
\end{tabular}

highest average density with the lowest standard deviation. The porosity characterization (Table 3 ) is in good agreement with the density measurements: sample $\mathrm{C}$, which contains the lowest number of pores (0.06 vol.\% A-type porosity and no B-type), is denser than the others. On the opposite, sample $\mathrm{B}$ contains the highest amount of porosity and presents thus a low density: its microstructure shows 0.6 vol.\% of A-type porosity and $0.02 \mathrm{vol} \%$ of B-type porosity. Samples $\mathrm{D}$ and $\mathrm{E}$ possess, respectively, 0.2 and 0.06 vol.\% A-type porosity and 0.02 vol.\% B-type porosity. No free carbon porosity (C-type porosity) was found in the samples.

Figure 5 presents the microstructures of the ball-milled samples etched with the Murakami reagent. The finest microstructure is found in sample C (Fig. 5b). Samples milled in dry conditions show local growths of WC grains (Fig. 5a for a rotation speed of $300 \mathrm{rpm}$ and Fig. 5c for a rotation speed of $600 \mathrm{rpm})$. The so-called nest-like growth of uniform-sized WC (300 rpm) and the so-called "local giant WC growth" (600 rpm) are dispersed within the microstructure. According to Schubert et al. [10], these local growths might have different origins: coarser WC particles already present in the green bodies (formed during the processing of the powders) or irregularities (localized high carbon concentration, extremely fine agglomerates with increased reactivity). The samples milled in ethanol do not show local growth of WC grains and the grains are better dispersed in the microstructure. However, $\eta$-phase can be seen (see the black area in Fig. 5b and the electronic supplementary material).

As shown in Fig. 6, SEM images present the grain size distribution of the sintered samples: samples milled in wet conditions exhibit smaller grains than the samples milled in dry conditions. Moreover, the grain size distributions are narrower in the case of milling in ethanol, with $97 \%$ of the grains having a size smaller than $2 \mu \mathrm{m}$. Sample B (dry milling-300 rpm) has the largest grains. The average grain sizes are 935 and $875 \mathrm{~nm}$ for dry milling (300 and $600 \mathrm{rpm}$, respectively) and 760 and $765 \mathrm{~nm}$ for wet milling (300 and $600 \mathrm{rpm}$, respectively). Wet milling ensures a better distribution of the particles in the powders and thus fewer local growths as shown in dry milling. The limited diffusion processes in dry milling make the powders more prone to local growths. As said in Schubert et al. [10], local growths appear at around $1250{ }^{\circ} \mathrm{C}$ and cannot be eliminated at the sintering temperature. The lower grain size in the wet-milled samples can be attributed to the formation of $\eta$-phase after sintering: indeed, Konyashin et al. [55] have shown that the limiting step for grain coarsening in WC-Co is linked to the carbon self-diffusion in tungsten carbide grains towards the interface between liquid cobalt and solid WC grains.

\section{Mechanical Properties}

Figure 7 shows the mechanical properties of the different samples (hardness and fracture toughness). The samples milled in ethanol showed higher hardness, between 1800 and $1900 \mathrm{HV}_{30}\left(\mathrm{C}: 1867 \pm 37 \mathrm{HV}_{30}\right.$ and E: $1821 \pm 21$ $\left.\mathrm{HV}_{30}\right)$. The samples milled in dry conditions exhibit similar hardness around $1700 \mathrm{HV}_{30}\left(\mathrm{~B}: 1695 \pm 20 \mathrm{HV}_{30}\right.$ and $\mathrm{D}$ : $\left.1709 \pm 23 \mathrm{HV}_{30}\right)$. The higher hardness in wet-milled samples is explained by the smaller grain size and the narrower grain size distributions: as the average grain size decreases, the hardness is higher according to the Hall-Petch relationship [56]. The fracture toughness of the samples is around $10.50 \mathrm{MPa} \sqrt{ } \mathrm{m}$ for all samples except for samples B which show a slightly higher $(11 \mathrm{MPa} \sqrt{\mathrm{m}})$ toughness. A hypothesis to explain that higher value comes from the local nest-like growths dispersed within the microstructure. In cemented tungsten carbides, the crack propagation is predominant across the binder. Nest-like growths are concentrations of WC grains with a lower amount of binder. The local lower amount of binder makes the propagation of the cracks more difficult, leading to higher fracture toughness values. The fracture toughness of the samples from experiment A (Turbula mixed powder) could not be evaluated due to the presence of many pores inside the microstructure.

Moreover, the observations agree with Bonache et al. [43], who have found that the distribution of the elements 

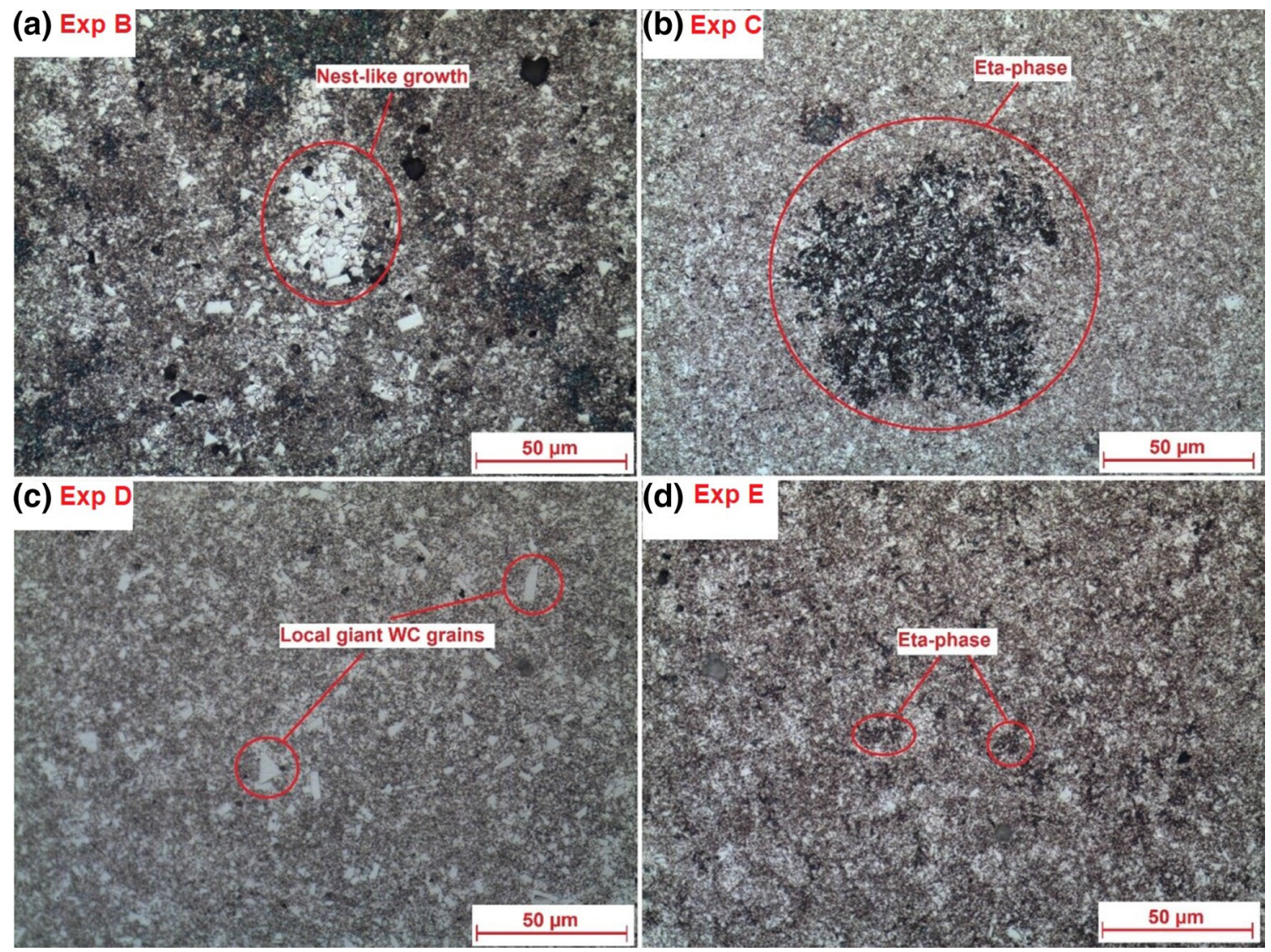

Fig. 5 Microstructures of the samples after etching by Murakami $(\times 500)$ : a dry milling at $300 \mathrm{rpm}$, b wet milling at $300 \mathrm{rpm}$, c dry milling at $600 \mathrm{rpm}$, $\mathbf{d}$ wet milling at $600 \mathrm{rpm}$

caused by wet milling is better than in dry milling and thus enhances the sintering process, which leads to better mechanical properties. On the opposite, the influence of the rotation speed on hardness and fracture toughness is not significant (see experiments B vs. D or experiments $C$ vs. $\mathrm{E}$ in Fig. 7). The limited influence of the rotation speed on mechanical properties could be attributed to the similar grain size distributions: for wet milling, the distribution is narrow, and few grains are above $2 \mu \mathrm{m}$, while in dry milling, more grains have a size higher than $2 \mu \mathrm{m}$.

\section{Discussion}

In 2010 , only $25 \%$ of the tungsten carbide production came from recycled scraps. Within this $25 \%$, around $50 \%$ of the recycled WC powder was processed by the zinc process while the other $50 \%$ was chemically transformed into APT [45]. As a direct recycling method, the Coldstream process has the advantages of a high recovery rate and the production of a chemically pure powder (the powder has the same composition as the used scraps). Moreover, no further conversion steps or chemical adjustments are needed.

As shown in this paper, the recycled powder cannot be sintered in conventional conditions without a milling step. The powder was thus ball milled in different conditions to optimize the process. The milling is not an additional step because it is already widely used in the industry to mix the different powders (WC, Co, inhibitors): no time and energy will be lost during the ball milling of the recycled powder.

Figure 8 shows a correlation graph between hardness and average grain size (obtained from the grain size distributions of Fig. 6). The wet-milled samples (C and E) have significantly higher mechanical properties and narrower grain size distributions. The best milling conditions were thus found to be a rotation speed of $300 \mathrm{rpm}$ in wet medium (ethanol): they lead to samples with the narrowest grain size distribution, the lowest amount of porosity, without local WC grain growth, and with the highest mechanical properties. Lower rotation speed is preferred to limit the temperature as well as the energy consumption during the milling of the powder. The formation of the eta-phase is a drawback of wet milling and is usually detrimental to mechanical properties $[52,57$, 

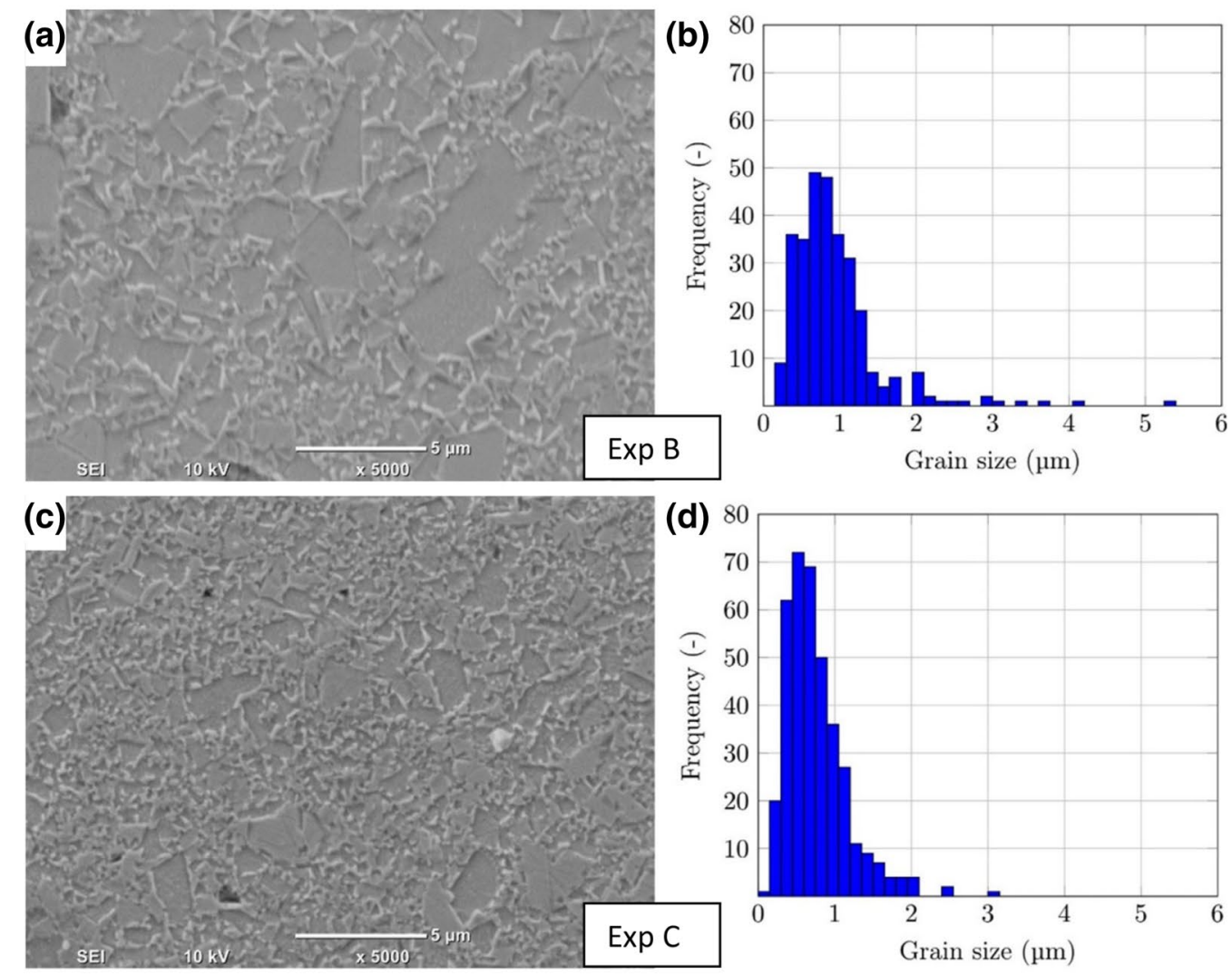

(e)
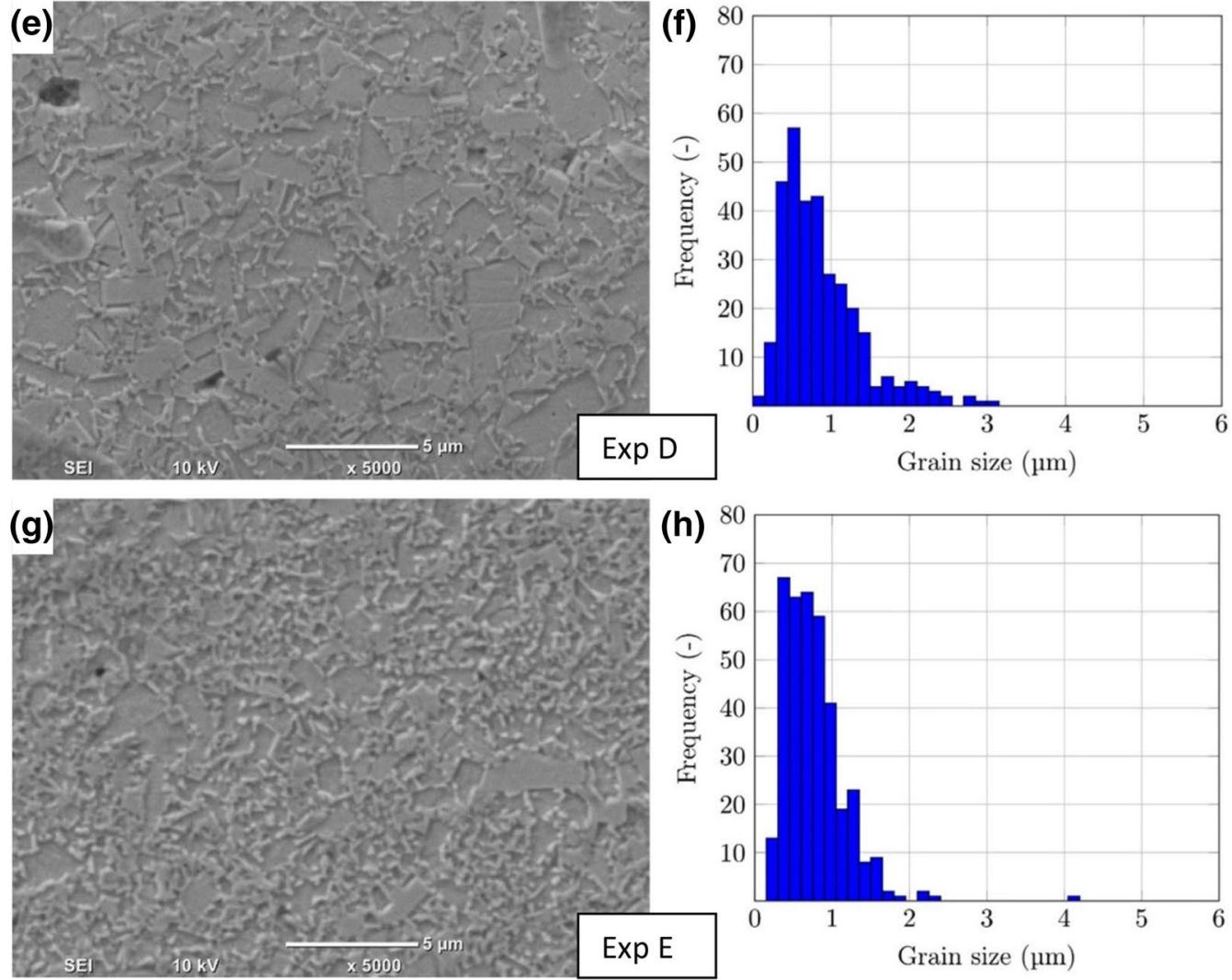

Fig. 6 SEM images $(\times 5000)$ and corresponding grain size distribution: $\mathbf{a}, \mathbf{b}$ dry milling at $300 \mathrm{rpm}, \mathbf{c}, \mathbf{d}$ wet milling at $300 \mathrm{rpm}, \mathbf{e}, \mathbf{f}$ dry milling at $600 \mathrm{rpm}, \mathbf{g}$, h wet milling at $600 \mathrm{rpm}$ 

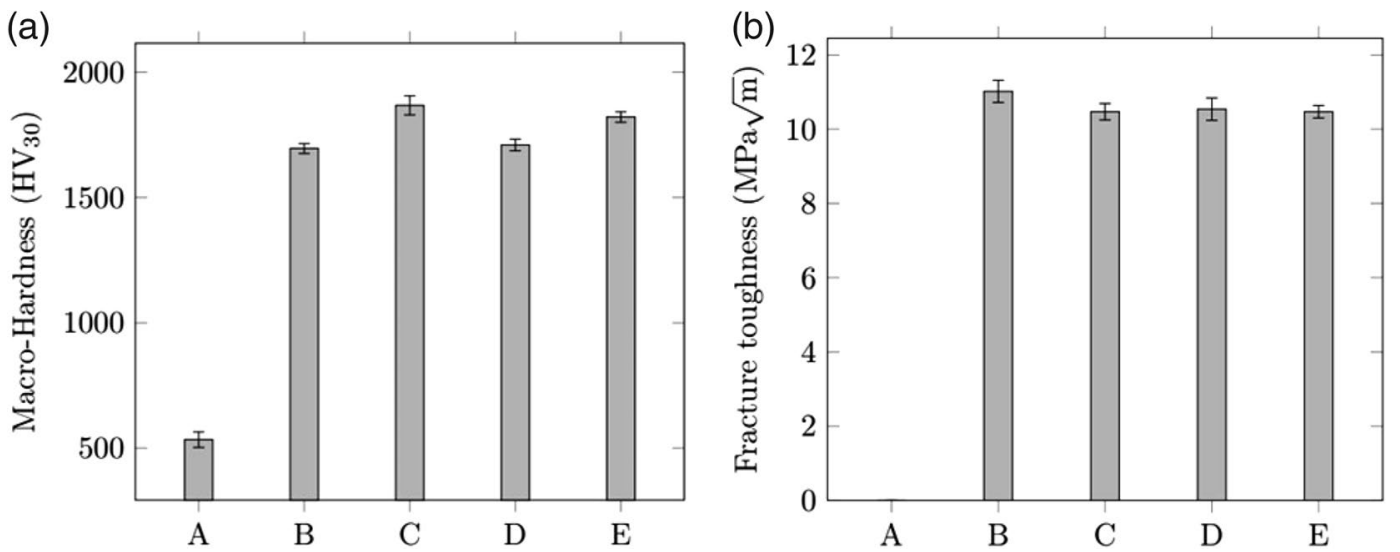

Fig. 7 Mechanical properties: a macro-hardness vickers $\mathrm{HV}_{30}$, b Palmqvist fracture toughness. $A$ turbula mixed power, $B$ dry milling at $300 \mathrm{rpm}$, $C$ wet milling at $300 \mathrm{rpm}, D$ dry milling at $600 \mathrm{rpm}, E$ wet milling at $600 \mathrm{rpm}$

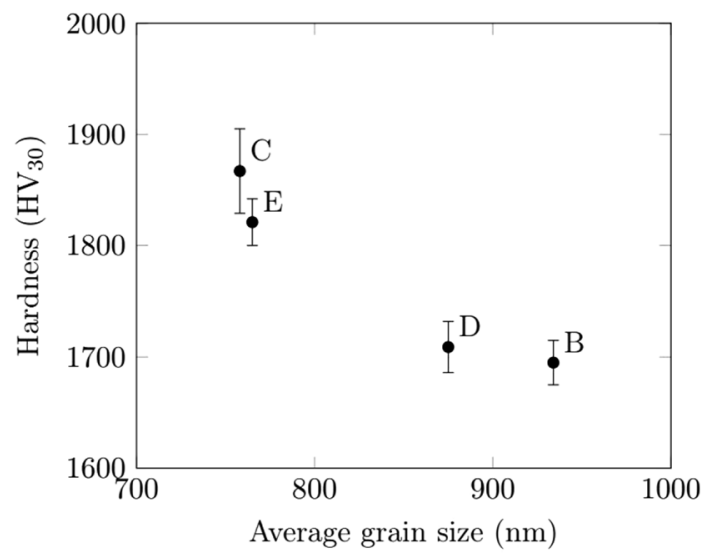

Fig. 8 Correlation between hardness and average grain size: $B$ dry milling at $300 \mathrm{rpm}, C$ wet milling at $300 \mathrm{rpm}, D$ dry milling at $600 \mathrm{rpm}, E$ wet milling at $600 \mathrm{rpm}$

58]. However, in this work, the amount of eta-phase is low and thus the mechanical properties are only slightly affected: hardness is the highest, and fracture toughness competes with dry-milled samples.

In the review of García et al. [57], it is shown that for 7.5 wt. $\%$ cobalt, the Vickers hardness varies between 1400 and $1800 \mathrm{HV}_{30}$ depending on the grain size $(5-1 \mu \mathrm{m})$. Moreover, the literature shows that non-recycled WC-7.5Co and WC-8Co have been sintered by conventional process with lower mechanical properties [59-61]. The results found in this paper are comprised between 1700 and $1850 \mathrm{HV}_{30}$. Processed with an optimized milling step, the crushed recycled powder is thus a cheaper alternative to conventional powders. An increase in the use of recycled WC-Co powders is beneficial to face the numerous issues related to cobalt and tungsten extraction, as well as the constant increase of the raw materials' price. As China produces most of the tungsten in the world and holds the main producers of cobalt, the use of recycled powders could help overcome the dependency on Chinese exports.

\section{Conclusion}

Ball milling experiments have been undertaken to increase the sinterability of a recycled WC-Co powder, which has been sintered at $1500{ }^{\circ} \mathrm{C}$ by vacuum sintering. The temperature was chosen to ensure full density.

Without ball milling, dense sintered WC-Co parts are challenging to obtain by usual sintering conditions. Wet milling ensures a narrower grain size distribution and allows higher mechanical properties. No local growths were found in wet-milled samples, but $\eta$-phase was observed (a sign of decarburization). The influence of the rotation speed is limited (lower rotation speed is slightly better).

The best combination of mechanical properties and grain size is obtained after wet milling at a rotation speed of $300 \mathrm{rpm}$. The properties of samples milled in those conditions are $1870 \mathrm{HV}_{30}, 10.50 \mathrm{MPa} \sqrt{ } \mathrm{m}$, and average grain size of about $760 \mathrm{~nm}$. Tungsten carbide-cobalt recycled powder can be used for the processing of WC-Co parts. The main advantage of that powder is its lower price in comparison with raw WC and Co powders. Its drawbacks are the need for ball milling to improve the sinterability of the powder, and the cobalt content which is fixed at 7.5 wt.\%. However, with an optimized ball milling step, the recycled powder can fully compete with conventional powders.

Supplementary Information The online version contains supplementary material available at https://doi.org/10.1007/s40831-021-00346-2. 
Acknowledgements The authors would like to thank the Höganäs company for providing the recycled powder and the oxygen and carbon measurements, as well as the Belgian Ceramic Research Centre (BCRC) for the Scanning Electron Microscopy.

\section{Declarations}

Conflict of Interest On behalf of all authors, the corresponding author states that there is no conflict of interest.

Open Access This article is licensed under a Creative Commons Attribution 4.0 International License, which permits use, sharing, adaptation, distribution and reproduction in any medium or format, as long as you give appropriate credit to the original author(s) and the source, provide a link to the Creative Commons licence, and indicate if changes were made. The images or other third party material in this article are included in the article's Creative Commons licence, unless indicated otherwise in a credit line to the material. If material is not included in the article's Creative Commons licence and your intended use is not permitted by statutory regulation or exceeds the permitted use, you will need to obtain permission directly from the copyright holder. To view a copy of this licence, visit http://creativecommons.org/licenses/by/4.0/.

\section{References}

1. European Commission (2019) "Critical raw materials". https://ec. europa.eu/growth/sectors/raw-materials/specific-interest/critical_ en. Accessed 18 Mar 2019

2. US Department of Interior (2019) "Critical minerals". https:// www.doi.gov/pressreleases/interior-seeks-public-comment-draftlist-35-minerals-deemed-critical-us-national. Accessed 17 Dec 2019

3. Shedd KB, Mccullough EA, Bleiwas DI (2017) Global trends affecting the supply security of cobalt. Min Eng 69(12):37-42

4. Hofmann M, Hofmann H, Hagelüken C, Hool A (2018) Critical raw materials: a perspective from the materials science community. Sustain Mater Technol 17:e00074

5. Løvik AN, Hagelüken C, Wäger P (2018) Improving supply security of critical metals: current developments and research in the EU. Sustain Mater Technol 15:9-18

6. Sun X, Hao H, Liu Z, Zhao F, Song J (2019) Tracing global cobalt flow : 1995-2015. Resour Conserv Recycl 149:45-55

7. Kapusta JPT (2006) Cobalt production and markets: a brief overview. J Miner 58(10):33-36

8. Harper EM, Kavlak G, Graedel TE (2012) Tracking the metal of the goblins: cobalt's cycle of use. Environ Sci Technol 46:1079-1086

9. Allibert CH (2001) Sintering features of cemented carbides WC-Co processed from fine powders. Int J Refract Metals Hard Mater 19(1):53-61

10. Schubert WD, Bock A, Lux B (1995) General aspects and limits of conventional ultrafine WC powder manufacture and hard metal production. Int J Refract Met Hard Mater 13(5):281-296

11. Wu CC, Chang SH, Tang TP, Peng KY, Chang WC (2016) Study on the properties of WC-10Co alloys adding $\mathrm{Cr}_{3} \mathrm{C}_{2}$ powder via various vacuum sintering temperatures. J Alloys Compd 686:810-815

12. Lavergne O, Robaut F, Hodaj F, Allibert CH (2002) Mechanism of solid-state dissolution of WC in Co-based solutions. Acta Mater 50:1683-1692
13. Exner H (1979) Physical and chemical nature of cemented carbides. Int Mater Rev 24(4):149-173

14. Upadhyaya G (2001) Materials science of cemented carbides: an overview. Mater Des 22(6):483-489

15. Chang SH, Chang MH, Huang KT (2015) Study on the sintered characteristics and properties of nanostructured WC-15 wt $\%$ (Fe$\mathrm{Ni}-\mathrm{Co}$ ) and WC-15 wt\% Co hard metal alloys. J Alloys Compd 649:89-95

16. Zhao Z, Liu J, Tang H, Ma X, Zhao W (2015) Investigation on the mechanical properties of WC-Fe-Cu hard alloys. J Alloys Compd 632:729-734

17. Zhao Z, Liu J, Tang H, Ma X, Zhao W (2015) Effect of Mo addition on the microstructure and properties of WC-Ni-Fe hard alloys. J Alloys Compd 646:155-160

18. Chang SH, Chen SL (2014) Characterization and properties of sintered WC-Co and WC-Ni-Fe hard metal alloys. J Alloys Compd 585:407-413

19. Zhou PF, Xiao DH, Yuan TC (2016) Comparison between ultrafine-grained WC-Co and WC-HEA-cemented carbides. Powder Metall 60(1):1-6

20. Velo IL, Gotor FJ, Alcalá MD, Real C, Córdoba JM (2018) Fabrication and characterization of WC-HEA cemented carbide based on the CoCrFeNiMn high entropy alloy. J Alloys Compd 746:1-8

21. Lassner E, Schubert WD (1999) Tungsten: properties, chemistry. Technology of the Element, Alloys, and Chemical Compounds, New York

22. Shemi A, Magumise A, Ndlovu S, Sacks N (2018) Recycling of tungsten carbide scrap metal: a review of recycling methods and future prospects. Miner Eng 122:195-205

23. Bhosale SN, Mookherjee S, Pardeshi RM (1990) Current practices in tungsten extraction and recovery. High Temp Mater Process $9(2-4): 147-162$

24. Kuntyi OI, Ivashkin VR, Yavorskii VT, Zozulya GI (2007) Electrochemical processing of WC-Ni pseudoalloys in sulfuric acid solutions to ammonium paratungstate and nickel(II) sulfate. Russ J Appl Chem 80(11):1856-1859

25. Latha TM, Venkatachalam S (1989) Electrolytic recovery of tungsten and cobalt from tungsten carbide scrap. Hydrometallurgy 22:353-361

26. Takahashi R, Yuize T (1958) Method of chemically disintegrating and pulverizing solid material. US Patent no. 2,848,313

27. Jonsson KA (1971) Process for chlorination of material containing hard metal. US Patent no. 3,560,199

28. Edtmaier $\mathrm{C}$ et al (2005) Selective removal of the cobalt binder in WC/Co based hardmetal scraps by acetic acid leaching. Hydrometallurgy 76:63-71

29. Kim S, Seo B, Son S (2014) Dissolution behavior of cobalt from WC-Co hard metal scraps by oxidation and wet milling process. Hydrometallurgy 143:28-33

30. Seo B, Kim S (2016) Cobalt extraction from tungsten carbidecobalt (WC-Co) hard metal scraps using malic acid. Int J Miner Process 151:1-7

31. Sun F, Chen X, Zhao Z (2018) Anodic passivation on the recycling of cemented carbide scrap by selective electro-dissolution. Waste Manag 80:285-291

32. Freemantle CS, Sacks N, Topic M, Pineda-vargas CA (2014) Impurity characterization of zinc-recycled WC-6 wt.\% Co cemented carbides. Int J Refract Met Hard Mater 44:94-102

33. Freemantle CS, Sacks N (2015) The impact of zinc recycling on the slurry rheology of WC -6 wt.\% Co cemented carbides. Int J Refract Metals Hard Mater 49:99-109

34. Eso OO (2016) Densification and sintering shrinkage of zinc Reclaimed WC-Co. Int J Refract Met Hard Mater 54:445-454 
35. Srivastava RR, Lee J, Bae M, Kumar V (2019) Reclamation of tungsten from carbide scraps and spent materials. J Mater Sci 54(1):83-107

36. Lassner E, Schubert WD (1999) Tunsgten scrap recycling, Chap. 11. Tungsten: properties, chemistry, technology of the element, alloys and chemical compounds. Springer, Boston, pp 377-385

37. El-Eskandarany MS, Mahday AA, Ahmed HA, Amer AH (2000) Synthesis and characterizations of ball-milled nanocrystalline WC and nanocomposite WC-Co powders and subsequent consolidations. J Alloys Compd 312:315-325

38. Suryanarayana C (2001) Mechanical alloying and milling. Prog Mater Sci 46:1-184

39. Zhang FL, Zhu M, Wang CY (2008) Parameters optimization in the planetary ball milling of nanostructured tungsten carbide/ cobalt powder. Int J Refract Met Hard Mater 26:329-333

40. Raihanuzzaman R, Sik T, Ghomashchi R, Xie Z, Hong S (2014) Characterization of short-duration high-energy ball milled WC-Co powders and subsequent consolidations. J Alloys Compd 615:S564-S568

41. Enayati MH, Aryanpour GR, Ebnonnasir A (2009) Production of nanostructured WC-Co powder by ball milling. Int J Refract Met Hard Mater 27(1):159-163

42. Fayyaz A, Muhamad N, Sulong AB, Yunn HS, Amin SYM, Rajabi $\mathrm{J}$ (2012) Effect of dry and wet ball milling process on critical powder loading and mixture properties of fine WC-10Co-0.8VC powder. J Teknol 59:141-144

43. Bonache V, Salvador MD, Busquets D, Segovia EF (2011) Fabrication of ultrafine and nanocrystalline WC-Co mixtures by planetary milling and subsequent consolidations. Powder Metall 54(3):214-221

44. Xueming M, Ling Z, Gang J, Yuanda D (1997) Preparation and structure of bulk nanostructured WC-Co alloy by high energy ball-milling. J Mater Sci Lett 16:968-970

45. Leal-Ayala DR, Allwood JM, Petavratzi E, Brown TJ, Gunn G (2015) Mapping the global flow of tungsten to identify key material efficiency and supply security opportunities. Resour Conserv Recycl 103:19-28

46. Stanciu VI, Vitry V, Delaunois F (2017) Cobalt-inhibitor mixtures for cemented carbides. In: 19th Plansee Seminar. Reutte, pp. 1-12

47. Shetty DK, Wright IG, Nincer PN, Clauer AH (1985) Indentation fracture of WC-Co cermets. J Mater Sci 20:1873-1882

48. Schubert WD, Neumeister H, Kinger G, Lux B (1998) Hardness to toughness relationship of fine-grained WC-Co hardmetals. Int J Refract Met Hard Mater 16(2):133-142

49. Meredith B, Milner DR (1976) Densification mechanisms in the tungsten carbide-cobalt system. Powder Metall 19(1):38-45
50. Oliver CJRG, Álvarez EA, García JL (2016) Kinetics of densification and grain growth in ultrafine WC-Co composites. Int J Refract Met Hard Mater 59:121-131

51. Zhang M, Cheng Z, Li J, Qu S, Li X (2019) Study on microstructure and mechanical properties of WC-10Ni3Al cemented carbide prepared by different ball-milling suspension. Materials 12(2224):1-12

52. Ponomarev SS, Shatov AV, Mikhailov AA, Firstov SA (2015) Carbon distribution in WC based cemented carbides. Int J Refract Met Hard Mater 49:42-56

53. Hewitt SA, Kibble KA (2009) Effects of ball milling time on the synthesis and consolidation of nanostructured WC-Co composites. Int J Refract Met Hard Mater 27(6):937-948

54. Gheisari K, Javadpour S, Oh JT, Ghaffari M (2009) The effect of milling speed on the structural properties of mechanically alloyed $\mathrm{Fe}-45 \%$ Ni powders. J Alloys Compd 472:416-420

55. Konyashin I et al (2009) On the mechanism of WC coarsening in WC-Co hardmetals with various carbon contents. Int J Refract Met Hard Mater 27(2):234-243

56. Richter V, Ruthendorf M (1999) On hardness and toughness of ultrafine and nanocrystalline hard materials. Int J Refract Met Hard Mater 17:141-152

57. García J, Ciprés VC, Blomqvist A, Kaplan B (2019) Cemented carbide microstructures: a review. Int J Refract Met Hard Mater 80:40-68

58. Joost R, Pirso J, Tenno T, Viljus M (2010) Effect of free carbon on the mechanical and tribological properties of cemented carbides. In: 7th International DAAAM Baltic Conference. Tallinn, pp. 1-6

59. Raihanuzzaman R, Han S, Ghomashchi R, Kim H, Hong S (2015) Conventional sintering of WC with nano-sized Co binder: characterization and mechanical behavior. Int J Refract Met Hard Mater $53: 2-6$

60. Su W, Sun Y, Feng J, Liu J, Ruan J (2015) Influences of the preparation methods of WC-Co powders on the sintering and microstructure of coarse grained WC-8Co hardmetals. Int J Refract Met Hard Mater 48:369-375

61. Dvornik MI, Zaytsev AV, Mikhailenko EA (2012) Influence of defects on strength and hardness of submicron WC-8Co- $1 \mathrm{Cr}_{3} \mathrm{C}_{2}$ hard alloy. Phys Proced 23:73-76

Publisher's Note Springer Nature remains neutral with regard to jurisdictional claims in published maps and institutional affiliations.

\section{Authors and Affiliations}

\section{Alexandre Mégret ${ }^{1}\left[\right.$ [D $\cdot$ Véronique Vitry ${ }^{1} \cdot$ Fabienne Delaunois $^{1}$}

Alexandre Mégret

alexandre.megret@umons.ac.be

Véronique Vitry

veronique.vitry@umons.ac.be

Fabienne Delaunois

fabienne.delaunois@umons.ac.be
1 Metallurgy Lab, University of Mons, 20 Place du Parc, 7000 Mons, Belgium 